\title{
Effect of the Holding Time during Solution Heat Treatment on Intergranular Corrosion of Unstabilized Austenitic Stainless Steels
}

\author{
Eun-Jong Oh*, Dong-Hwa Lee*, Sung-Woo Cho*, Yun-Il Choi**, ${ }^{\dagger}$ and Ki-Woo Nam*** \\ *Nuclear Business Group, Doosan Heavy Industries \& Construction Co. Ltd., Changwon, 51711, Korea \\ **Corporate R\&D Institute, Doosan Heavy Industries \& Construction Co. Ltd., Changwon, 51711, Korea \\ ***Depart. of Materials Science \& Engineering, Pukyong National University, Busan, 48513, Korea
}

†Corresponding author : yunil.choi@doosan.com

(Received November 5, 2019 ; Revised December 10, 2019 ; Accepted March 4, 2020)

\begin{abstract}
The holding time during solution heat treatment of unstabilized austenitic stainless steels as specified in the nuclear regulatory requirements was investigated. The sensitized $2.54 \mathrm{~cm}$ thick specimens held at $675^{\circ} \mathrm{C}$ for $1 \mathrm{~h}$ were rejected by ASTM A262 test, due to the large amount of chromium carbide precipitated in the form of 50 300nm particles at the grain boundaries. They also showed about $10.8 \%$ of DOS in the DL-EPR test. However, solution heat treatment of the sensitized specimens at $1,038^{\circ} \mathrm{C}$ and $1,121^{\circ} \mathrm{C}$ for at least 1 min resulted in the complete dissolution of chromium carbide into the grains, and they passed ASTM A262 test and showed less than $0.01 \%$ of DOS in the DL-EPR test. As a result of solution heat treatment at $1,038^{\circ} \mathrm{C}$ for $5 \mathrm{~h}$ of the $25.4 \mathrm{~cm}$ thick specimen sensitized at $675^{\circ} \mathrm{C}$ for $10 \mathrm{~h}$, it passed ASTM A262 and DL-EPR test at any position in the specimen thickness. While the specimen surface showed a step structure without the precipitation of chromium carbide and a DOS less than $0.01 \%$, towards the center, a dual structure was observed. It exhibited about $0.6 \%$ of DOS due to the longer exposure time to the sensitization range of $427 \sim 816^{\circ} \mathrm{C}$. Considering the minimum time in which the chromium carbide precipitated at the grain boundary at $1,038^{\circ} \mathrm{C}$ was completely dissolved into the grain, and the maximum delay time for the center of the specimen to reach $1,038^{\circ} \mathrm{C}$ rather than the surface, the holding time for complete solution heat treatment to the center was found to be up to $2 \mathrm{~min}$ per $2.54 \mathrm{~cm}$ of material thickness. The solution heat treatment for $0.5 \sim 1.0 \mathrm{~h}$ per $2.54 \mathrm{~cm}$ of material thickness at $1,038 \sim 1,121^{\circ} \mathrm{C}$, which is employed in the nuclear power industry, was proven to prevent grain boundary corrosion by inhibiting the sensitization of unstabilized austenitic stainless steels.
\end{abstract}

Key Words : Austenitic stainless steel, Solution heat treatment, Holding time, Intergranular corrosion

\section{Introduction}

Austenitic stainless steels have excellent corrosion resistance, heat resistance, fatigue resistance, machinability, weldability and cost efficiency due to its material properties with high strength, toughness, and ductility properties, accounting for more than $90 \%$ of stainless steels used in the nuclear power industry ${ }^{1}$. However, for nuclear facility components made from unstabilized austenitic stainless steels, such as type 304 and 316, rather than low-carbon grade stainless steels or stabilized stainless steels, such as type 321 and 347 , in the Safety Analysis Report, one of the nuclear regulatory requirements, exposure to the sensitization temperature range of 427 to $816^{\circ} \mathrm{C}$ is restricted in order to prevent the intergranular corrosion occurring in the chromium loss region near the grain boundary from the precipitation of chromium carbide $\left(\mathrm{Cr}_{23} \mathrm{C}_{6}\right)$. In addition, solution heat treatment, which is held at $1,038 \sim 1,121^{\circ} \mathrm{C}$ for $0.5 \sim 1.0$ hours per $2.54 \mathrm{~cm}$ of material thickness and then rapidly cooled, is proposed to inhibit the sensitization of the material. However, the ASME Section II Part A code, which is applied for the production of unstabilized stainless steel in the actual industrial site, specifies only the lower limit for the temperature of solution heat treatment, such as $1,038^{\circ} \mathrm{C}$ at minimum, for most materials, while the holding time for heat treat- 


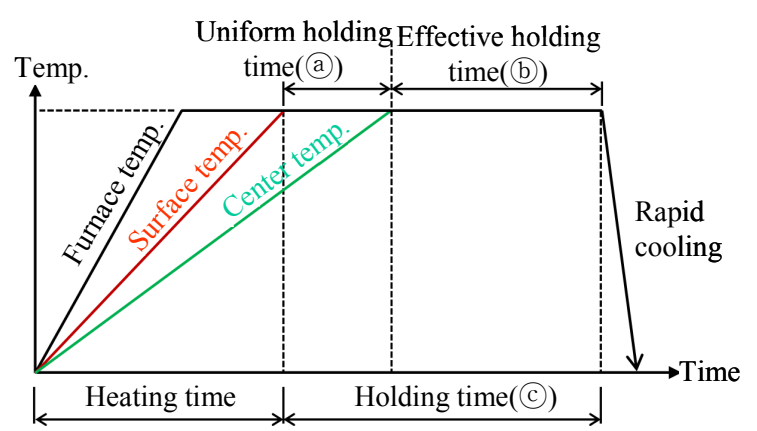

Fig. 1 Schematic diagram of solution heat treatment cycle

ment is not suggested. In this regard, the necessity of demonstration tests has emerged to establish the standards for specific solution heat treatment conditions ${ }^{2}$.

Accordingly, we investigated the effect of intergranular corrosion according to the solution heat treatment holding time and material thickness was investigated, and the time at which the center of the material reaches the solution heat treatment was analyzed as in Fig. 1. In the heat treatment cycle, uniform holding time (a) at which the solution heat treatment temperature is reached up to the center of the material, and the effective holding time (b) at which the chromium carbide was completely dissolved at the grain boundary after reaching the solution heat treatment temperature were experimented to determine the solution heat treatment holding time (C). These study results are expected to be the experimental reference data for the nuclear regulatory requirements and also to provide an opportunity in which the effectiveness of solution heat treatment conditions applied in the nuclear power industry is demonstrated.

\section{Experimental Method}

\subsection{Experiment preparation}

\subsubsection{Specimen and sensitization heat treatment}

This experiment was performed under conservative conditions reflecting the phenomenon that sensitization is more likely to occur as the carbon content is increased using austenitic stainless steel specimens of 0.074 wt. $\% \mathrm{C}$, which is higher than $0.065 \mathrm{wt} . \% \mathrm{C}$, the regulatory requirements on the maximum carbon content of the nuclear power industry. The chemical compositions of test coupons were analyzed with an inductively coupled plasma optical emission spectrometer, and the results are shown in Table 1.

Table 1 Chemical compositions(wt.\%) of test coupons

\begin{tabular}{|c|c|c|c|c|c|c|c|}
\hline Type & $\mathrm{C}$ & $\mathrm{Si}$ & $\mathrm{Mn}$ & $\mathrm{P}$ & $\mathrm{S}$ & $\mathrm{Ni}$ & $\mathrm{Cr}$ \\
\hline $\begin{array}{c}\text { A182 } \\
\text { F304H }\end{array}$ & 0.074 & 0.455 & 1.405 & 0.031 & 0.013 & 8.44 & 18.53 \\
\hline
\end{tabular}

To evaluate the effect on the solution heat treatment holding time, 10 coupons of $2.54 \mathrm{~cm}$ in thickness, $18 \mathrm{~cm}$ in width and $20 \mathrm{~cm}$ in length were prepared.

To evaluate the uniform holding time according to the material thickness, one coupon with a thickness of $25.4 \mathrm{~cm}$, a width of $48 \mathrm{~cm}$ and a length of $48 \mathrm{~cm}$ was prepared. At this time, the coupon thickness of $25.4 \mathrm{~cm}$ is based on the consideration of the maximum thickness of austenitic stainless steels used in the nuclear power industry, and the coupon with a width and length greater than this thickness was prepared to exclude the effect on the thickness direction.

The above coupons were heated at a rate of $100^{\circ} \mathrm{C} / \mathrm{h}$, held at $675^{\circ} \mathrm{C}$ for 1 hour per $2.54 \mathrm{~cm}$ of coupon thickness, and then water cooled for sensitization heat treatment. For comparative evaluation before and after the solution heat treatment, the specimens subjected to sensitization heat treatment were collected from the surface of the coupons before conducting the solution heat treatment.

It is known that as the stress applied to the material increases, the resulting strain increases the chromium diffusion rate, leading to the acceleration of the chromium carbide precipitation at the grain boundary and increase in the sensitization, but the effect of external stress is excluded in this experiment ${ }^{3)}$.

\subsubsection{Solution heat treatment}

For the investigation of the effect on the solution heat treatment holding time, the coupons with a thickness of $2.54 \mathrm{~cm}$ subjected to sensitization heat treatment at $675^{\circ} \mathrm{C}$. for 1 hour were held for 1 minute, 5 minutes, 10 minutes, 15 minutes, and 30 minutes at a minimum temperature of $1,038^{\circ} \mathrm{C}$. and a maximum temperature of $1,121^{\circ} \mathrm{C}$, and then water cooled, and the heating rate was $100^{\circ} \mathrm{C}$ $/ \mathrm{h}$. At this time, the specimens were taken from the surface area of the coupons to minimize the effect from the thickness.

In order to evaluate the uniform holding time according to the material thickness, a $25.4 \mathrm{~cm}$ coupon subjected to sensitization heat treatment at $675^{\circ} \mathrm{C}$ for 10 hours was heated with a heating rate of $50^{\circ} \mathrm{C} / \mathrm{h}$ to a minimum temperature of $1,038^{\circ} \mathrm{C}$ of solution heat treatment specified in nuclear regulatory requirements, then it was held for 5 hours and water cooled. At this time, the minimum temperature was set considering that the lower the heat treatment temperature, the longer it takes to apply uniform heat up to the center of the material, and the test was conducted under conservative conditions by applying 0.5 hour per $2.54 \mathrm{~cm}$, the minimum holding time of nuclear regulatory requirements. After 


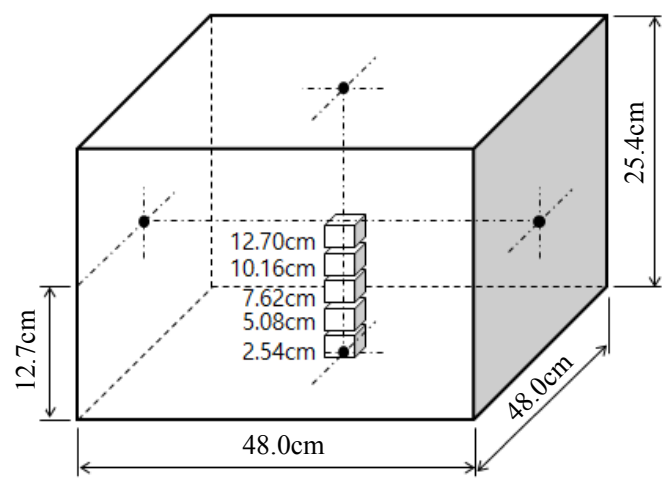

Fig. 2 Specimen sampling location for evaluation by solution heat treatment per material thickness

the solution heat treatment, as shown in Fig. 2, specimens were collected at the coupon surface and at depths of $2.54 \mathrm{~cm}, 5.08 \mathrm{~cm}, 7.62 \mathrm{~cm}, 10.16 \mathrm{~cm}$ and $12.70 \mathrm{~cm}$ spaced 1 inch apart from the coupon surface. In addition, before the solution heat treatment, the thermocouples were separately installed on the surface and at the center of the coupon so that the difference between the surface and the center can be measured for the time it took to reach $1,038^{\circ} \mathrm{C}$, the solution heat treatment temperature, and the time exposed to the sensitization temperature range of 427 to $816^{\circ} \mathrm{C}$ in the cooling process.

\subsection{Test and analysis methods}

\subsubsection{Intergranular corrosion by chemical immersion}

In order to evaluate the effect of chromium carbide precipitation of austenitic stainless steel on intergranular corrosion, an intergranular corrosion test was conducted in accordance with requirements of ASTM A262 Practice A and E specified by nuclear regulatory requirements ${ }^{4)}$.

In the ASTM A262 Practice A test, $25 \times 25 \times 12 \mathrm{~mm}$ specimen was immersed in a $10 \%$ oxalic acid solution at room temperature in which $100 \mathrm{~g}$ of oxalic acid $\left(\mathrm{C}_{2} \mathrm{H}_{2} \mathrm{O}_{4} \cdot 2 \mathrm{H}_{2} \mathrm{O}\right)$ was dissolved in $900 \mathrm{ml}$ of distilled water, current was applied for 90 seconds with the current density of $1 \mathrm{~A} / \mathrm{cm}^{2}$, and then the degree of intergranular corrosion on the surface was observed by an optical microscope with 250 times magnification. In the ASTM A262 Practice E test, after dissolving $100 \mathrm{~g}$ of copper sulfate $\left(\mathrm{CuSO}_{4} \cdot 5 \mathrm{H}_{2} \mathrm{O}\right)$ in $700 \mathrm{ml}$ of distilled water, $100 \mathrm{ml}$ of sulfuric acid $\left(\mathrm{H}_{2} \mathrm{SO}_{4}\right)$ was added, and $80 \times 15 \times$ $3 \mathrm{~mm}$ specimen was immersed in a solution diluted to $1,000 \mathrm{ml}$ with distilled water and boiled for 15 hours. Then, a bending test was performed to observe whether grain boundary cracks were generated by an optical microscope with 60 times magnification.

\subsubsection{Microstructure observation and composition analysis}

Chromium carbide existed in the grain boundary according to the sensitization heat treatment and solution heat treatment was observed through TEM (Transmission electron microscopy) images of replica specimens, and through SAD (Selected area diffraction) patterns and EDS (Energy dispersive X-ray spectroscopy) analysis, the types and compositions of grain boundary precipitate were analyzed.

\subsubsection{Intergranular corrosion by electrochemical po- larization}

To supplement the ASTM A262 intergranular corrosion test, which has a limitation in the quantitative representation of the degree of sensitization, a DL-EPR (Double Loop Electrochemical Potentiokinetic Reactivation) test was performed according to ASTM G108 and ISO12732 requirements ${ }^{5,6)}$. The specimen was polished to $1 \mu \mathrm{m}$ with silicone carbide paper and alumina paste, and then ultrasonic cleaning was performed in ethanol and distilled water for 5 minutes each. The specimen was immersed in $1 \mathrm{~L}$ of $0.5 \mathrm{M} \mathrm{H}_{2} \mathrm{SO}_{4}+0.01 \mathrm{M} \mathrm{KSCN}$ solution at $30^{\circ} \mathrm{C}$ aerated to simulate the environment during operation of the nuclear facility components, and then from a potential $-50 \mathrm{mV}$ lower than the natural corrosion potential $\left(\mathrm{E}_{\mathrm{OC}}\right)$ measured for 30 minutes of open circuit delay time, anodic polarization was performed up to $+200 \mathrm{mV}_{\mathrm{SCE}}$, at a constant scanning rate of $1.667 \mathrm{mV} / \mathrm{s}$, and then reverse scanning was performed ${ }^{7}$. Saturated calomel electrodes (SCE) and high- purity carbon rods were used as reference and counter electrodes, respectively. The ratio $\left(\mathrm{I}_{\mathrm{r}} / \mathrm{I}_{\mathrm{p}}\right)$ of the maximum current $\left(\mathrm{I}_{\mathrm{p}}\right)$ for the activation during the forward anodic polarization to the maximum current (Ir) for the selective reactivation of chromium loss region during reverse polarization was used as a measure to calculate the degree of sensitization (DOS) that represents the degree of the intergranular corrosion ${ }^{3,8,9)}$.

\subsubsection{Finite Element Method (FEM)}

After the surface of the material reached the solution heat treatment temperature of $1,038^{\circ} \mathrm{C}$, the uniform holding time at which the central part reached the same temperature was analyzed for evaluation using ANSYS program as shown in Fig. 3. In the first stage, an analytical methodology was established through the creating of a model for test validation, heat transfer analysis, comparison with thermocouple measurement results, correction of initial conditions, and confirmation of analysis property values. In the second stage, the time to reach the solution heat treatment temperature at the surface and at the center was calculated by creating a 


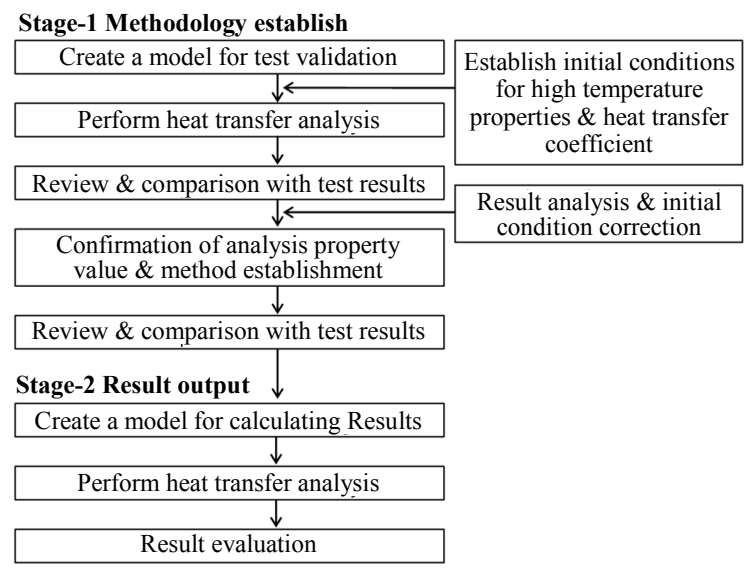

Fig. 3 Schematic sequence diagram of uniform holding time analysis by ANSYS (ver. 15.07) program

model for calculating results, analyzing heat transfer and evaluating the results. For the analysis of uniform time to reach the solution heat treatment temperature, convective heat transfer analysis considering natural convection phenomenon in the heat treatment furnace was performed and for the analysis input, the temperature heating rate in the heat treatment furnace was applied. As for the analysis result, the time to reach the solution heat treatment temperature at each of surface and center was derived and the uniform holding time, which is the difference between the two times, was calculated.

Twelve analytical models with different thicknesses (T) and widths (W) were selected to form a three-dimensional rectangular shape to encompass the specimen size and heat transfer characteristics to which solution heat treatment was performed. As for the length (L), 5 times the width (W) was applied so as not to affect the analysis result. Table 2 shows the analytical

Table 2 Evaluation analytical models of uniform holding time during solution heat treatment $\left(1,038^{\circ} \mathrm{C}, 5 \mathrm{~h}\right)$

\begin{tabular}{|c|c|c|c|c|}
\hline \multicolumn{2}{|c|}{ Analytical models } & \multirow{2}{*}{$\begin{array}{l}\text { Thickness } \\
(\mathrm{T}, \mathrm{cm})\end{array}$} & \multirow{2}{*}{$\begin{array}{c}\text { Width } \\
(\mathrm{W}, \mathrm{cm})\end{array}$} & \multirow{2}{*}{$\begin{array}{l}\text { Length } \\
(\mathrm{L}, \mathrm{cm})\end{array}$} \\
\hline Type & No. & & & \\
\hline \multirow{7}{*}{$\begin{array}{l}\text { Models for } \\
\text { calculating } \\
\text { results }\end{array}$} & TM1* & 25.4 & 50.8 & 50.8 \\
\hline & RM1 & 38.1 & 2.54 & 12.7 \\
\hline & RM2 & 38.1 & 12.7 & 63.5 \\
\hline & RM3 & 38.1 & 25.4 & 127.0 \\
\hline & RM4 & 38.1 & 38.1 & 190.5 \\
\hline & RM5 & 25.4 & 2.54 & 12.7 \\
\hline & RM6 & 25.4 & 12.7 & 63.5 \\
\hline \multirow{6}{*}{$\begin{array}{l}* \text { TM1 : Model } \\
\text { for test } \\
\text { verification }\end{array}$} & RM7 & 25.4 & 25.4 & 127.0 \\
\hline & RM8 & 12.7 & 2.54 & 12.7 \\
\hline & RM9 & 12.7 & 6.35 & 31.75 \\
\hline & RM10 & 12.7 & 12.7 & 63.5 \\
\hline & RM11 & 2.54 & 1.27 & 6.35 \\
\hline & RM12 & 2.54 & 2.54 & 12.7 \\
\hline
\end{tabular}

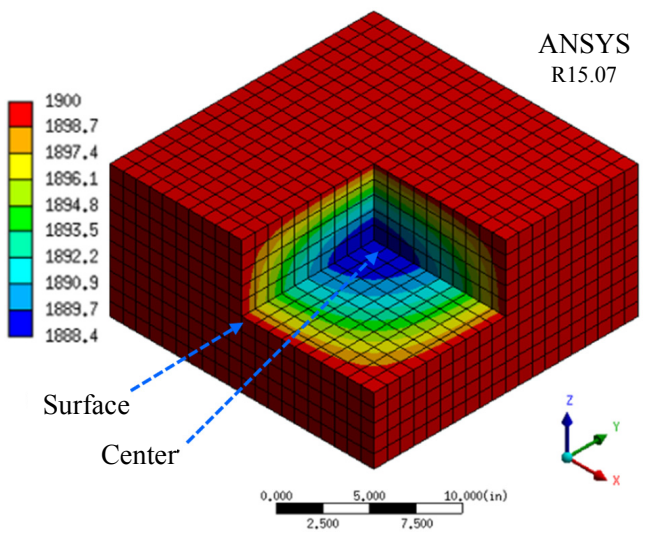

Fig. 4 The model geometry of finite element method

model for evaluating the uniform holding time, and Fig. 4 shows the model geometry of the finite element analysis model.

As for the property values applied to the uniform holding time analysis, the material properties of austenitic stainless steel (304 SS) of ASME Section III Part $\mathrm{D}$ were used as initial conditions and for the area exceeding the temperature range provided by the ASME code, a quadratic polynomial was assumed for the curve fitting to apply for the initial analysis ${ }^{2)}$. In order to determine the analytical properties of final application, the thermocouple measurement results were compared with the initial analysis results and the initial properties were modified to simulate the thermocouple measurement results. At this time, the thermal conductivity and specific heat value of $2,000^{\circ} \mathrm{F}$ were modified, and at the temperature below that, the properties provided by the ASME code were applied. Heat treatment heating rate was applied at $50^{\circ} \mathrm{C} / \mathrm{h}$, convection heat transfer coefficient was applied at $0.009 \mathrm{BTU} / \mathrm{hr} \cdot \mathrm{in}^{2} \cdot{ }^{\circ} \mathrm{F}$.

\section{Test Results and Discussion}

\subsection{Effect evaluation of solution heat treatment holding time}

The high intergranular corrosion resistance of austenitic stainless steel required by the nuclear power industry is greatly affected by the process parameters of solution heat treatment during the material production process that determines the solubility of precipitates near the grain boundary ${ }^{1,10)}$. Therefore, ASTM A262 Practice A and E, TEM, and DL-EPR tests have been conducted to investigate the effect of heat treatment temperature of $1,038 \sim 1,121^{\circ} \mathrm{C}$, the solution heat treatment condition specified in the nuclear regulatory requirements, and the holding time of $0.5 \sim 1.0$ per $2.54 \mathrm{~cm}$ on the intergranular corrosion.

In the specimen with the thickness of $2.54 \mathrm{~cm}$ sub- 


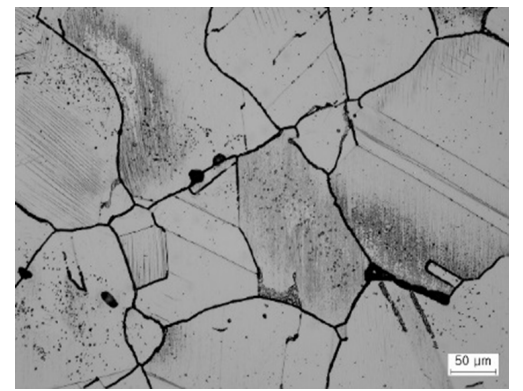

Fig. 5 Etch structures on the sensitized $2.54 \mathrm{~cm}$-thick specimen $\left(675^{\circ} \mathrm{C}\right.$ for $\left.1 \mathrm{~h}, \mathrm{WC}\right)$ by ASTM A262 Practice A test $(\times 250)$

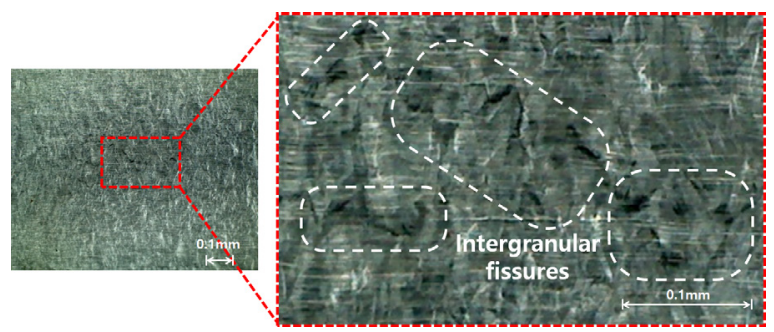

Fig. 6 Bent area view of the sensitized $2.54 \mathrm{~cm}$-thick specimen $\left(675^{\circ} \mathrm{C}\right.$ for $\left.1 \mathrm{~h}, \mathrm{WC}\right)$ by ASTM A262 Practice E test $(\times 60)$

jected to sensitization at $675^{\circ} \mathrm{C}$ for 1 hour before performing solution heat treatment, ditch structure, in which the sensitization by chromium carbide continuously precipitated at the grain boundary is suspected, was observed in the ASTM A262 Practice A test, as shown in Fig. 5. Also, as in Fig. 6, in the ASTM A262 Practice E test, micro cracks in micro fissure form were observed in the bent areas on which the bending test was conducted. It is known that the formation of these micro fissures is due to the ditch structure caused by intergranular corro$\operatorname{sion}^{11)}$.

For analyzing the causes of forming the ditch structure and micro cracks in the form of micro fissures observed in the ASTM A262 practice test, TEM analysis was performed as shown in Fig. 7, and it was possible to verify the presence of chromium carbide $\left(\mathrm{Cr}_{23} \mathrm{C}_{6}\right)$ of the FCC structure clustered in the form of nanoparticles with a diameter of about $50 \sim 300 \mathrm{~nm}$ at the grain boundary. From this result, it is thought that the ditch structure and micro cracks identified in the surface of the sensitized specimen is caused by the precipitation of chromium carbide at the grain boundary.

On the other hand, in all specimens subjected to solution heat treatment for 1 minute, 5 minutes, $10 \mathrm{mi}$ nutes, 15 minutes and 30 minutes at $1,038^{\circ} \mathrm{C}$ and $1,121^{\circ} \mathrm{C}$, as shown in Fig. 8 and Fig. 9, chromium carbide at grain boundary which was continuously precipitated in the ASTM A262 Practice A test was completely dis-
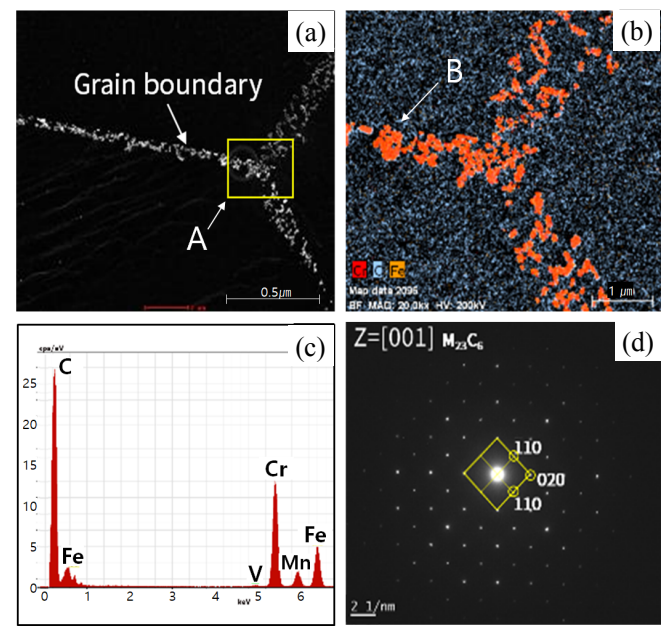

Fig. 7 TEM analysis results of the sensitized $2.54 \mathrm{~cm}$ thick specimen $\left(675^{\circ} \mathrm{C}\right.$ for $\left.1 \mathrm{~h}, \mathrm{WC}\right)$. (a) dark field image (x7k), (b) mapping on 'A' (20k), (c) EDS spectra on 'B', (d) SAD pattern on 'B', respectively
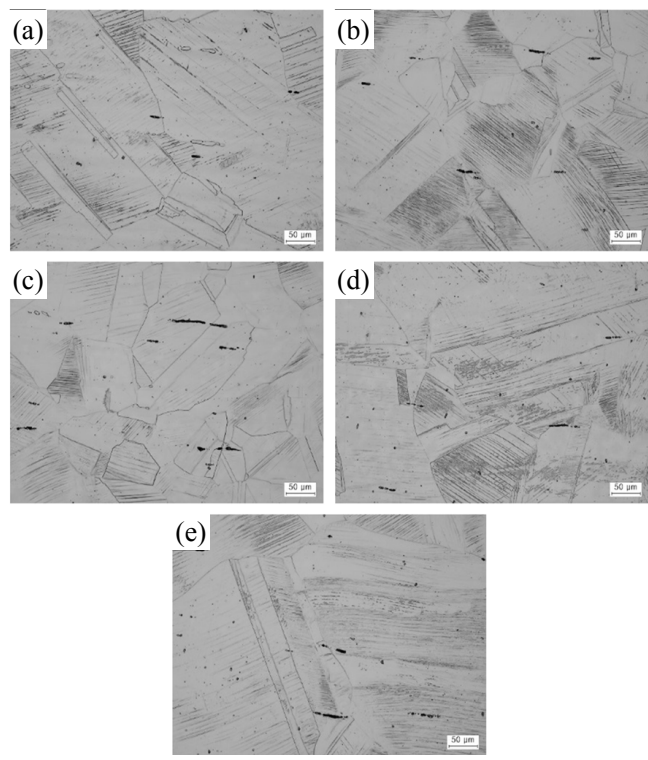

Fig. 8 Etch structures of the $2.54 \mathrm{~cm}$-thick specimens solution heat treated at $1,038^{\circ} \mathrm{C}$ for (a) $1 \mathrm{~min}$, (b) $5 \mathrm{~min}$, (c) 10min, (d) $15 \mathrm{~min}$, (e) 30min, respectively, by ASTM A262 Practice A test $(\times 250)$

solved and a step structure, which is the conforming structure that can pass the test was observed. Also, as in Fig. 10 and Fig. 11, in the ASTM A262 Practice E test, micro cracks of micro-fissure-type were not observed in the bent areas of the bending test.

The result of the observation of step structure without micro cracks in the ASTM A262 Practice test was consistent with the TEM analysis result of Fig. 12, in which the chromium carbide precipitated at the grain boundary was completely dissolved into the grains and disappeared through solution heat treatment at $1,038^{\circ} \mathrm{C}$ for 

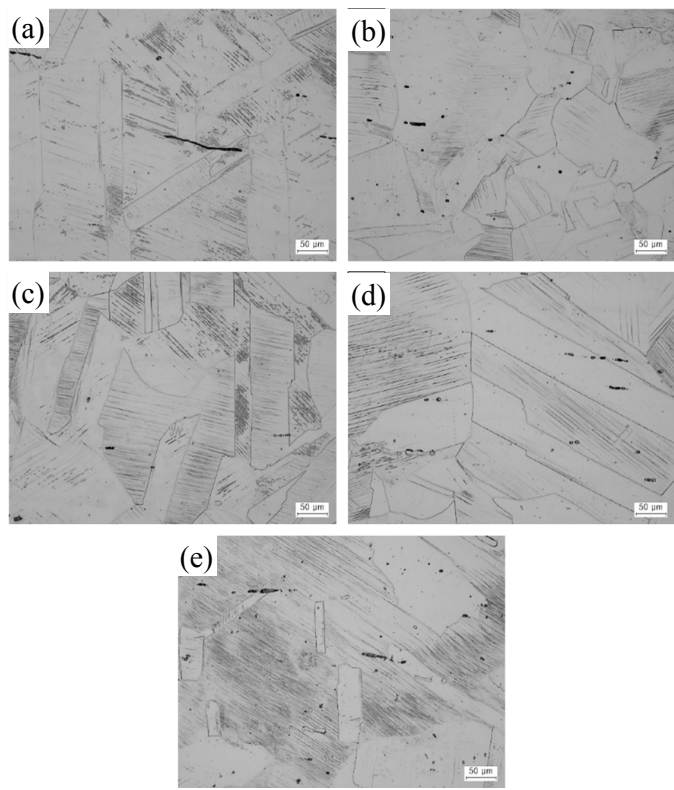

Fig. 9 Etch structures on the $2.54 \mathrm{~cm}$-thick specimens solution heat treated at $1,121^{\circ} \mathrm{C}$ for (a) $1 \mathrm{~min}$, (b) $5 \mathrm{~min}$, (c) $10 \mathrm{~min}$, (d) $15 \mathrm{~min},(\mathrm{e}) 30 \mathrm{~min}$, respectively, by ASTM A262 Practice A test $(\times 250)$
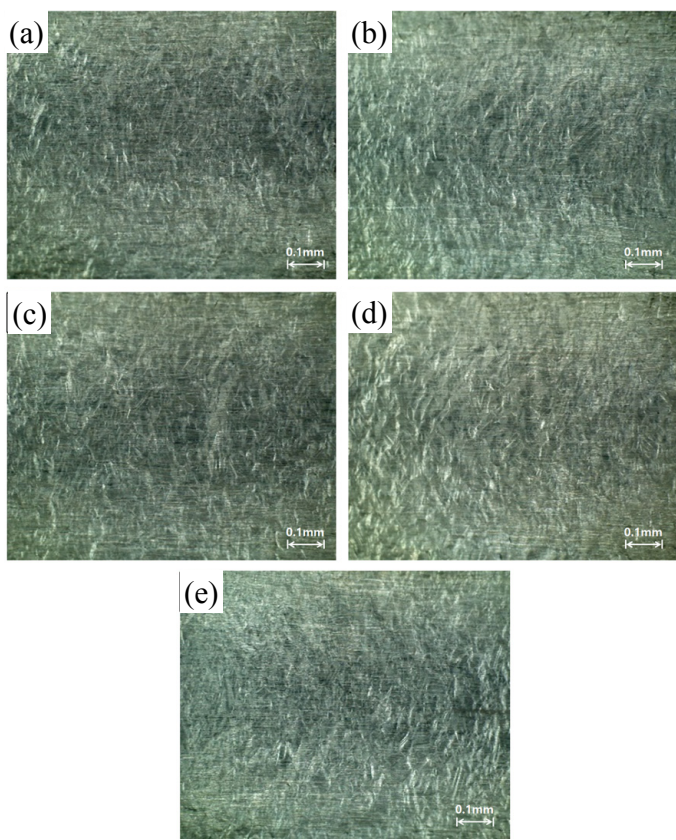

Fig. 10 Bent area view of the $2.54 \mathrm{~cm}$-thick specimens solution heat treated at $1,038^{\circ} \mathrm{C}$ for (a) $1 \mathrm{~min}$, (b) $5 \mathrm{~min},(\mathrm{c}) 10 \mathrm{~min}$, (d) $15 \mathrm{~min}$, (e) $30 \mathrm{~min}$, respectively, by ASTM A262 Practice E test $(\times 60)$.

1 minute or longer.

In order to analyze the correlation with ASTM A262 test according to sensitization heat treatment and solution heat treatment and to quantify DOS, a DL-EPR test was performed. As shown in Fig. 13 and Fig. 14, the corrosion potential of all specimens subjected to
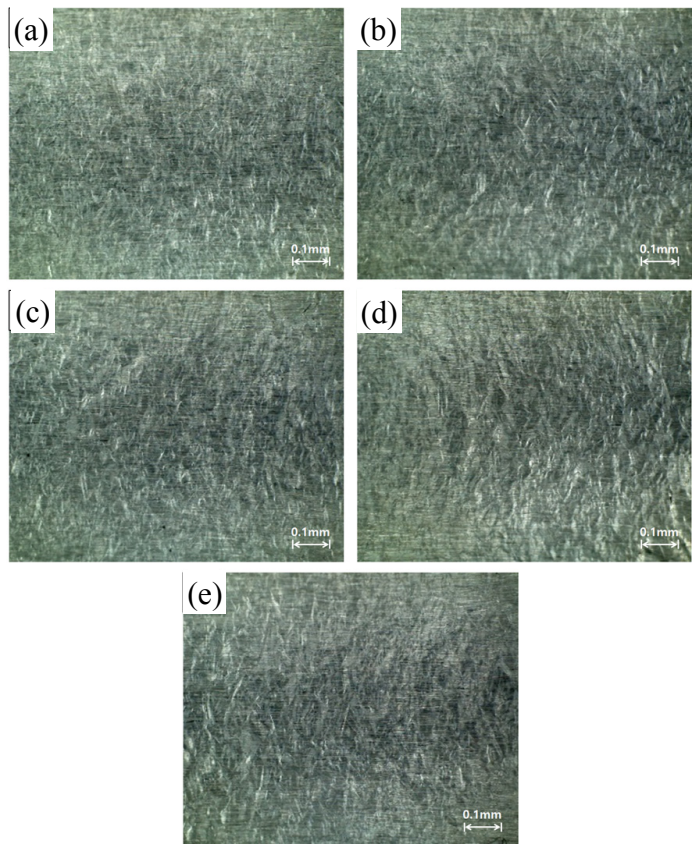

Fig. 11 Bent area view of the $2.54 \mathrm{~cm}$-thick specimens solution heat treated at $1,121^{\circ} \mathrm{C}$ for (a) $1 \mathrm{~min}$, (b) $5 \mathrm{~min}$, (c) $10 \mathrm{~min}$, (d) $15 \mathrm{~min}$, (e) 30min, respectively, by ASTM A262 Practice E test $(\times 60)$
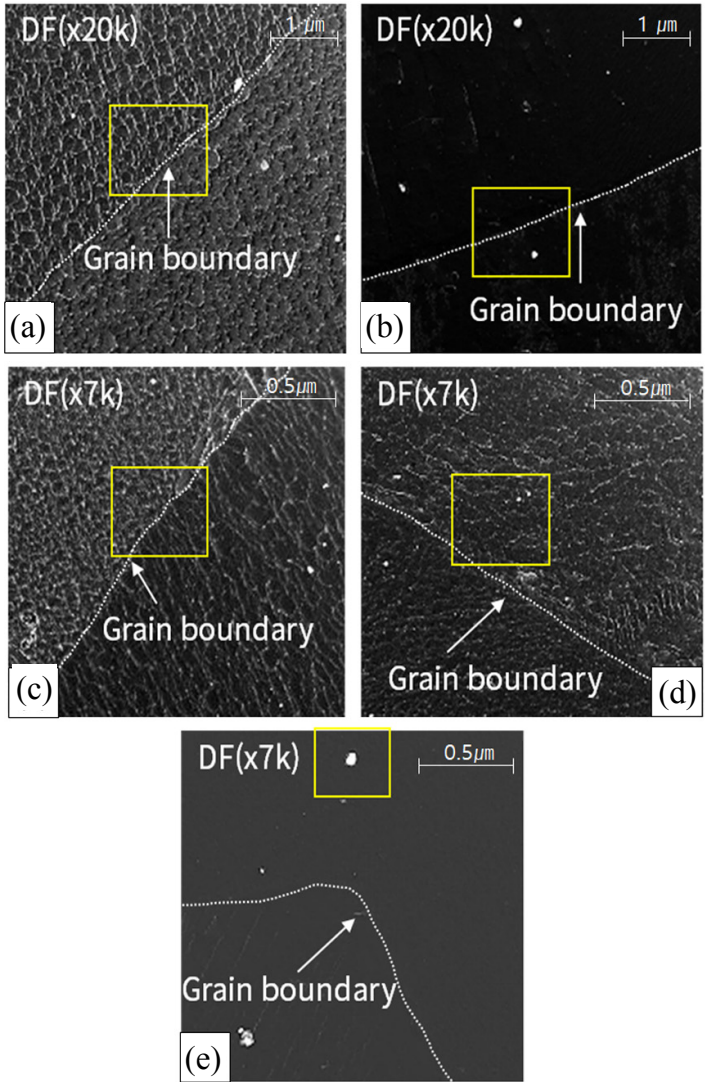

Fig. 12 TEM micrographs of the $2.54 \mathrm{~cm}$-thick specimens solution heat treated at $1,038^{\circ} \mathrm{C}$ for (a) $1 \mathrm{~min}$, (b) $5 \mathrm{~min}$, (c) 10min, (d) $15 \mathrm{~min}$, (e) $30 \mathrm{~min}$, respectively, $(\times 20 \mathrm{k}, \times 7 \mathrm{k})$ 


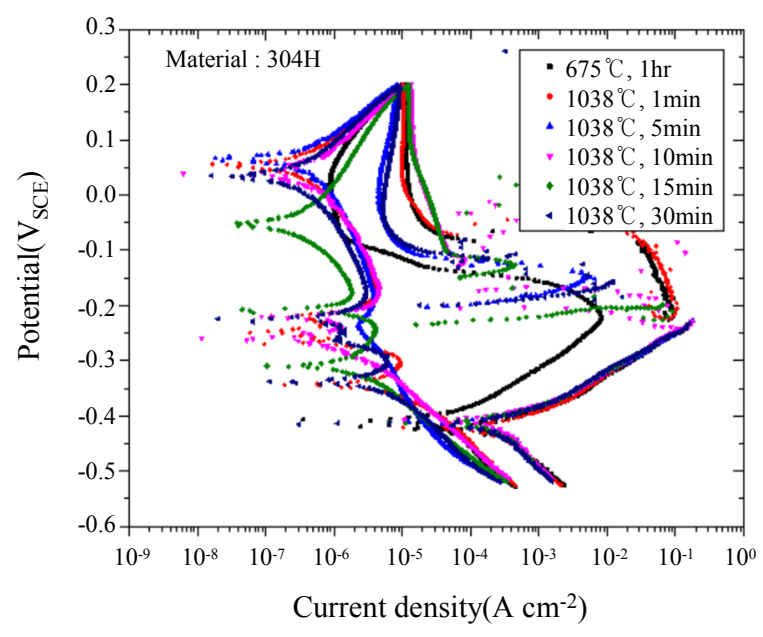

Fig. 13 DL-EPR curves of the $2.54 \mathrm{~cm}$-thick specimens sensitized at $675^{\circ} \mathrm{C}$ for $1 \mathrm{~h}(\mathrm{WC})$ and solution heat-treated at $1,038^{\circ} \mathrm{C}$ for $1 \sim 30 \mathrm{~min}(\mathrm{WC})$

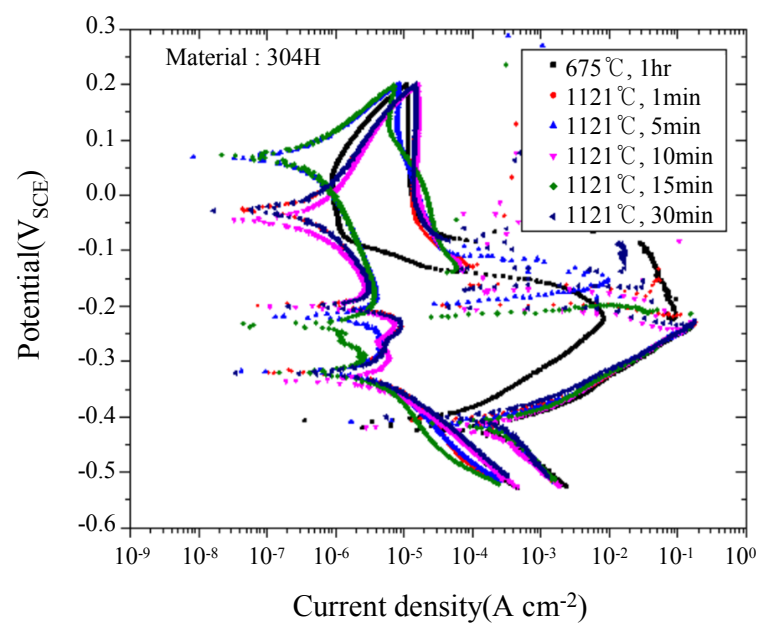

Fig. 14 DL-EPR curves of the $2.54 \mathrm{~cm}$-thick specimens sensitized at $675^{\circ} \mathrm{C}$ for $1 \mathrm{~h}(\mathrm{WC})$ and solution heat-treated at $1,121^{\circ} \mathrm{C}$ for $1 \sim 30 \mathrm{~min}$ (WC)

solution heat treatment was about $-0.4 \mathrm{~V}_{\mathrm{SCE}}$, regardless of the heat treatment temperature and holding time, and anodic dissolution reaction occurred from this corrosion potential to about $-0.2 \mathrm{~V}_{\mathrm{SCE}}$, the basic passivation potential. Thereafter, the potential reached about $+0.2 \mathrm{~V}_{\mathrm{SCE}}$, a passivation region accompanied by a decrease in current density. During the reverse potential scanning, two or more current peaks were observed by hydrogen reduction reaction and anodic dissolution reaction

As a result of calculating DOS $\left(\mathrm{I}_{\mathrm{r}} / \mathrm{I}_{\mathrm{p}} \times 100 \%\right)$, as shown in Fig. 15, sensitized specimens in which ditch structure and micro cracks in the form of micro fissures were observed showed DOS of about $10.8 \%$, and for all specimens with solution heat treatment of 1 minute or longer, DOS was reduced to about $0.01 \%$, indicating no occurrence of sensitization, and this was consistent with

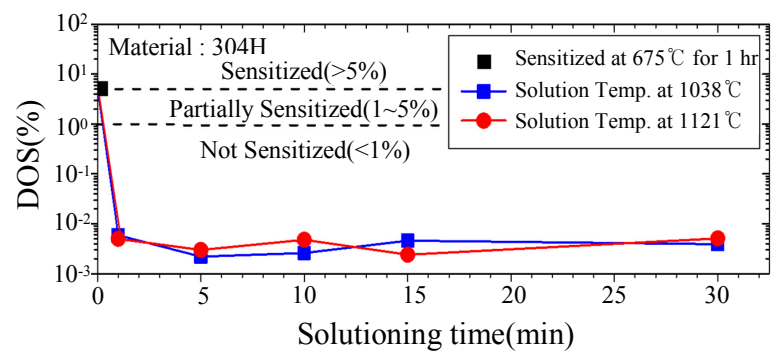

Fig. 15 DOS $(\operatorname{Ir} / \mathrm{Ip} \times 100 \%)$ of the sensitized and solution heat treated, $2.54 \mathrm{~cm}$-thick specimens calculated from Figs. 13 and 14

the ASTM A262 test results in which complete step structure was formed and no micro cracks of micro fissure type were observed. AS for the DOS evaluation, with the application of ISO-12732 standard, the standards were set to the occurrence of sensitization (DOS over 5\%), partial sensitization (DOS $1 \sim 5 \%$ ) and no sensitization (DOS less than $1 \%)^{6}$.

\subsection{Evaluation of uniform holding time according to material thickness}

As described above, an demonstration test on the sensitization with a maximum thickness of $25.4 \mathrm{~cm}$, which is the maximum thickness of austenitic stainless steel used in the nuclear power industry, was performed, and through the test, DOS was evaluated according to the location of each material thickness to verify the appropriateness of 0.5 hours per $2.54 \mathrm{~cm}$, the minimum holding time of solution heat treatment specified in nuclear regulatory requirements.

In the specimen with $25.4 \mathrm{~cm}$ thickness artificially sensitized for 10 hours at $675^{\circ} \mathrm{C}$ before the solution heat treatment, as shown in Fig. 16, ditch structure, in which sensitization by chromium carbide continuously precipitated at the grain boundary is suspected, was observed in the ASTM A262 Practice A test. Also, as shown in Fig. 17, micro cracks with a micro fissure-type were observed in the bent areas where the bend test was con-

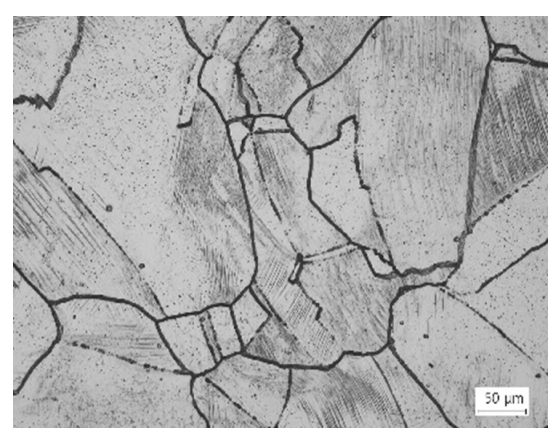

Fig. 16 Etch structures on the sensitized $25.4 \mathrm{~cm}$-thick specimen $\left(675^{\circ} \mathrm{C}\right.$ for $\left.10 \mathrm{~h}, \mathrm{WC}\right)$ by ASTM A262 Practice A test $(\times 250)$ 


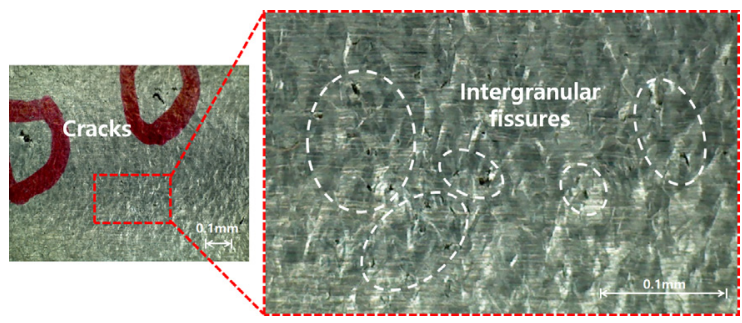

Fig. 17 Bent area view of the sensitized $25.4 \mathrm{~cm}$-thick specimen $\left(675^{\circ} \mathrm{C}\right.$ for $\left.10 \mathrm{~h}, \mathrm{WC}\right)$ by ASTM A262 Practice E test $(\times 60)$
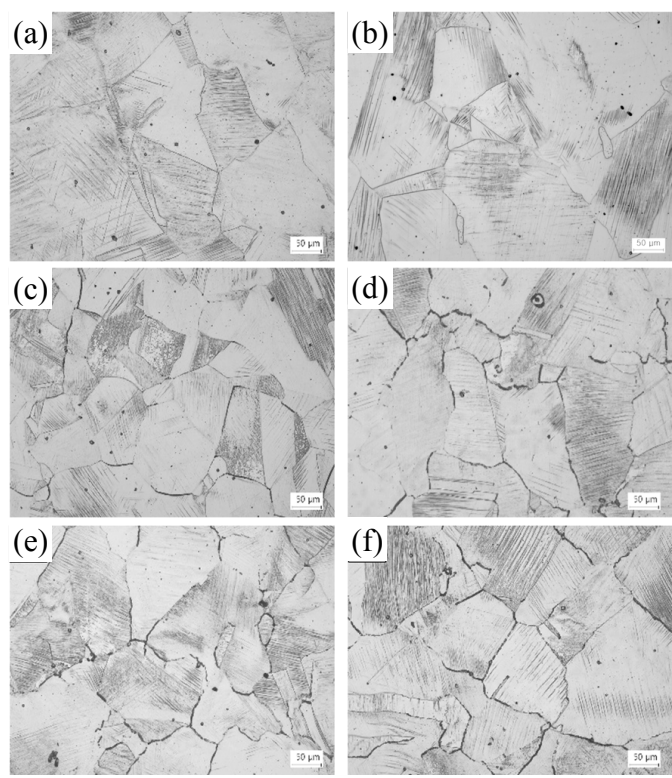

Fig. 18 Etch structures of the $25.4 \mathrm{~cm}$-thick specimen solution heat treated at $1,038^{\circ} \mathrm{C}$ for $5 \mathrm{~h}$. (a) $0 \mathrm{~cm}$ (surface), (b) $2.54 \mathrm{~cm}$, (c) $5.08 \mathrm{~cm}$, (d) $7.62 \mathrm{~cm}$, (e) $10.16 \mathrm{~cm}$, and (f) $12.70 \mathrm{~cm}$ away from the surface, respectively, by ASTM A262 Practice A test $(\times 250)$

ducted in the ASTM A262 Practice E test.

On the other hand, in the ASTM A262 Practice A test of a specimen subjected to solution heat treatment for 5 hours at $1,038^{\circ} \mathrm{C}$, step structure considered as an accepted structure, which is a conforming structure with no precipitation of chromium carbide at the grain boundary was observed, but dual structure considered as an accepted structure, another conforming structure formed by the discontinuous formation of chromium carbide due to the tendency of increasing precipitation of chromium carbide getting closer to the center part, was observed as in Fig. 18. This phenomenon is thought to have caused by longer exposure to the sensitization temperature range due to slower cooling rate at the center than the surface in the water cooling process of solution heat treatment. However, although dual structure was observed with the move from the surface to the center, no micro cracks in micro fissure type was ob-
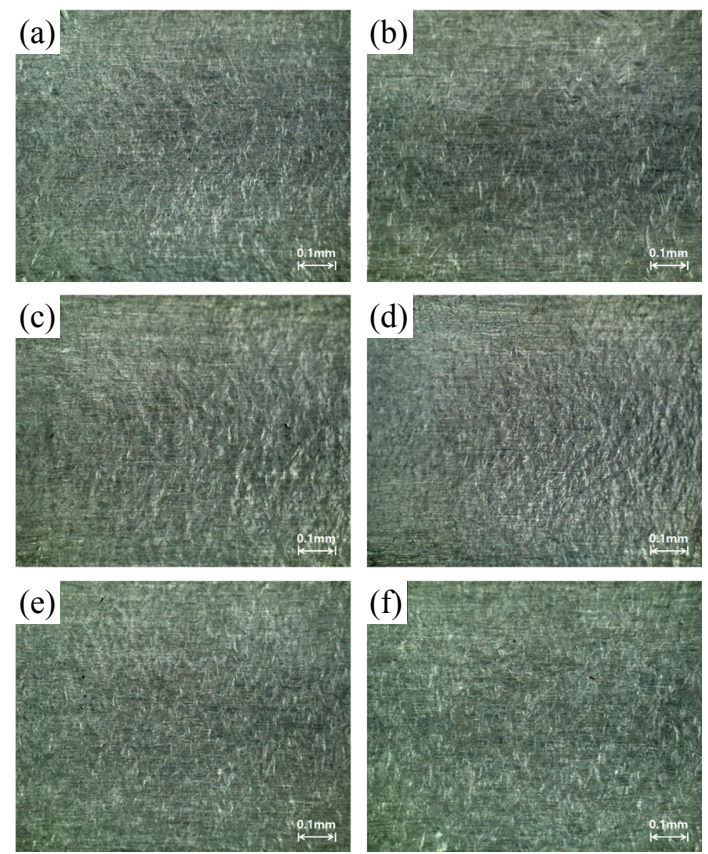

Fig. 19 Bent area view of the $25.4 \mathrm{~cm}$-thick specimen solution heat treated at $1,038^{\circ} \mathrm{C}$ for $5 \mathrm{~h}$. (a) $0 \mathrm{~cm}$ (surface), (b) $2.54 \mathrm{~cm}$, (c) $5.08 \mathrm{~cm}$, (d) $7.62 \mathrm{~cm}$, (e) $10.16 \mathrm{~cm}$, and (f) $12.70 \mathrm{~cm}$ away from the surface, respectively, by ASTM A262 Practice E test $(\times 60)$

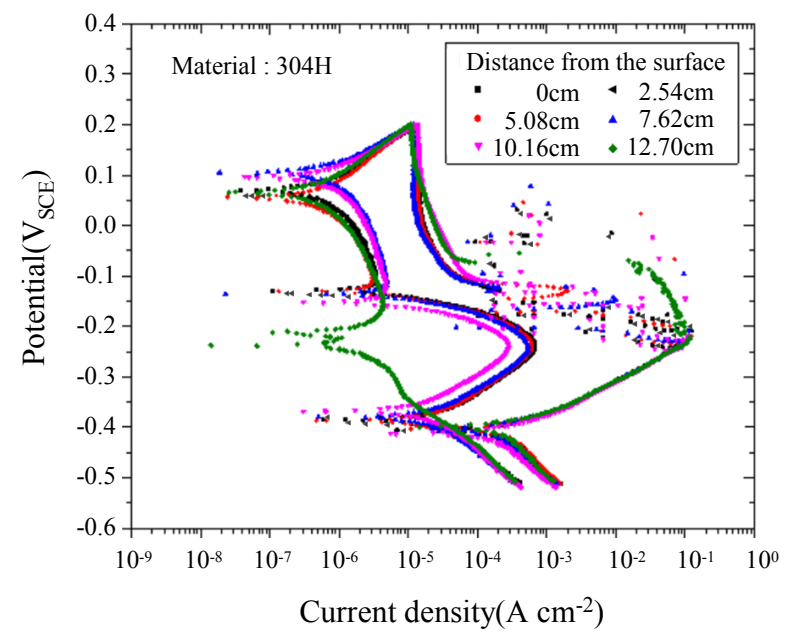

Fig. 20 DL-EPR curves of the $25.4 \mathrm{~cm}$-thick specimen solution heat treated at $1,038^{\circ} \mathrm{C}$ for $5 \mathrm{~h}$ with the distance from the surface

served in the bent areas of the bending test in ASTM A262 Practice E test, for all positions by thickness of the specimen, as shown in Fig. 19.

In order to analyze the correlation with ASTM A262 test by quantifying DOS of discontinuous chromium carbide formed according to the location per thickness of the material subjected to solution heat treatment, a DL-EPR test was performed. As shown in Fig. 20, the corrosion potential was about $-0.4 \mathrm{~V}_{\mathrm{SCE}}$, regardless of 


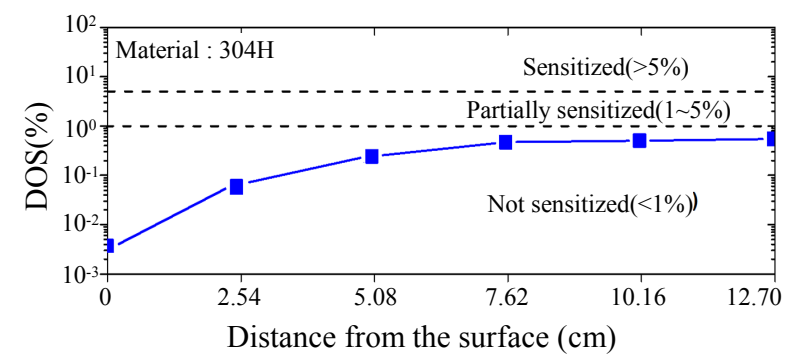

Fig. 21 DOS $\left(I_{r} / I_{p} \times 100 \%\right)$ of the $25.4 \mathrm{~cm}$-thick specimen solution heat-treated at $1,038^{\circ} \mathrm{C}$ for $5 \mathrm{~h}$ with the distance from the surface calculated from Fig. 20

the location per thickness, and anodic dissolution reaction occurred from this corrosion potential to about $-0.2 \mathrm{~V}_{\mathrm{SCE}}$, the basic passivation potential. Thereafter, the potential reached about $+0.2 \mathrm{~V}_{\mathrm{SCE}}$, a passivation region accompanied by a decrease in current density. During the reverse potential scanning, two or more current peaks were observed.

As a result of DL-EPR test, as shown in Fig. 21, the DOS on the surface was less than $0.01 \%$, but it was confirmed that the DOS increased with getting closer to the center, converging to about $0.6 \%$ at the depth of $12.7 \mathrm{~cm}$. This is considered to be the result of being exposed to the sensitization temperature range for a longer time because the cooling rate in the central part is slower than that in the surface, similar to the results of the ASTM A262 Practice A test. However, DOS less than $1 \%$ falls within the range of no occurrence of sensitization in the ISO-12732 standard, and given that there was no micro cracks observed in the ASTM A262 Practice E test, the same results that although ditch structure was observed getting closer to the center in the ASTM A262 Practice A test, the observed structure was considered as accepted structure were confirmed in the DL-EPR test.

In addition, as shown in Fig. 22, the thermocouple is separately installed on the surface and the central part.

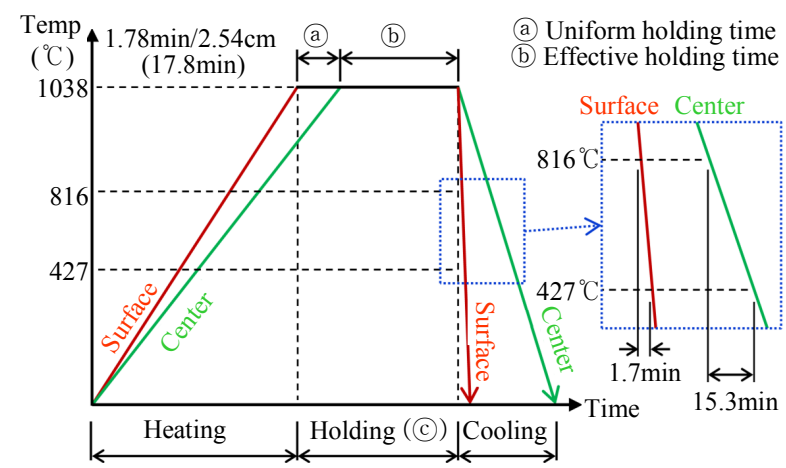

Fig. 22 Schematic diagram of the $25.4 \mathrm{~cm}$-thick specimen solution heat-treated at $1,038^{\circ} \mathrm{C}$ for $5 \mathrm{~h}$ measured by thermocouples
The measurement results show that, during the cooling process, the surface is briefly exposed for 1.7 minutes to the sensitization temperature range of $427 \sim 816^{\circ} \mathrm{C}$, while the central part is exposed for a long time of 15.3 minutes, support the test results, in which discontinuous dual structure was formed with the increase in the precipitation amount of the chromium carbide with a move closer to the center part and DOS was increased with its value converging to about $0.6 \%$.

However, considering that on the surface, the step structure with no precipitation of chromium carbide at all was observed and DOS of less than $0.01 \%$ was measured, and that the part directly affected by intergranular corrosion is the surface of the material, the results in the center part with the formation of dual structure and DOS of less than $0.01 \%$ are thought to have no effect on the for the nuclear facility components in the environment of those operation.

As for the results of finite element analysis on the uniform holding time for 12 analytical models according to the thickness and width of the material, Fig. 23 shows an example of the analytical model RM3 and the analysis results are presented in Fig. 24. In this case, the uniform holding time (a) in Fig. 22) refers to the time required for the central part to reach $1,038^{\circ} \mathrm{C}$ after

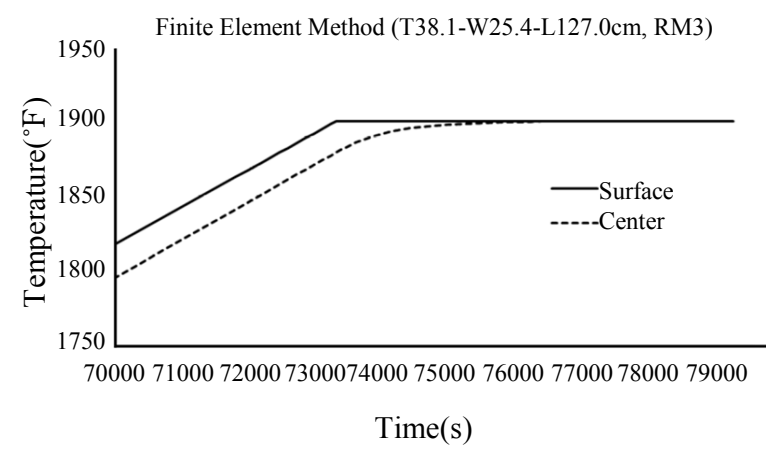

Fig. 23 FEM results of analytical model No. RM3

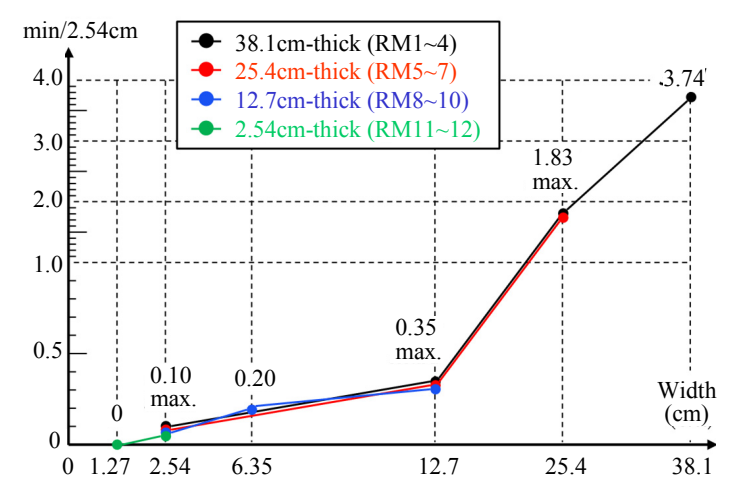

Fig. 24 Schemaic diagram for FEM results of 12 evaluation analytical models of uniform holding time during solution heat treatment at $1,038^{\circ} \mathrm{C}$ for $5 \mathrm{~h}$ 
the surface has reached $1,038^{\circ} \mathrm{C}$ divided by $2.54 \mathrm{~cm}$ per material thickness. The arbitrarily specified thickness or width of the material was not significant considering the heat transfer occurs by the shortest distance, and as the thinner of the thickness and width increased from $1.27 \mathrm{~cm}$ to $38.1 \mathrm{~cm}$, the uniform holding time increased from 0 minutes to 3.74 minutes per $2.54 \mathrm{~cm}$. It was confirmed that the rate of increase in uniform holding time increased as the thickness of the material increased. In this case, the uniform holding time for $25.4 \mathrm{~cm}$, the maximum material thickness used in the nuclear power industry, was evaluated to be 1.83 minutes per $2.54 \mathrm{~cm}$. This result was confirmed to be similar to the result in the thermocouple measurement test shown in Fig. 22 in which the center part reaches the temperature $1,038^{\circ} \mathrm{C}$ slower than the surface by 1.78 minutes (a) per $2.54 \mathrm{~cm}$. Based on these results, as a result of confirming the holding time (@) in Fig. 22) for solution heat treatment to the center of the material of $25.4 \mathrm{~cm}$, which is the maximum material thickness used in the nuclear power industry, after the center reaches $1,038^{\circ} \mathrm{C}$ for $18.3 \mathrm{mi}-$ nutes considering the uniform holding time (a) in Fig. 22) of 1.83 minutes per $2.54 \mathrm{~cm}$, considering 1 minute, which is the effective holding time (b) in Fig. 22) of solution heat treatment during which the chromium carbide precipitated at the grain boundary is completely dissolved into the grains at $1,038^{\circ} \mathrm{C}$ in the above effect evaluation of solution heat treatment holding time, the holding time for complete solution heat treatment to the center is calculated as about 19.3 minutes by addition. Therefore, from conservative viewpoint, the holding time for complete solution heat treatment to the center of the material was determined to be up to 2 minutes per $2.54 \mathrm{~cm}$ of the material thickness.

\section{Conclusion}

In this study, for the $0.74 \mathrm{wt} . \% \mathrm{C}$ stainless steel material, which is higher than the maximum carbon content regulation requirement of the nuclear power industry at $0.65 \mathrm{wt} . \% \mathrm{C}$, a test to verify the holding time according to the solution heat treatment temperature of the unstabilized austenitic stainless steels specified in the Safety Analysis Report, one of the nuclear regulatory requirements, was conducted, and an demonstration test considering the thickness $25.4 \mathrm{~cm}$, the maximum material thickness used in the nuclear power industry, was also included. As a result of these tests, the solution heat treatment conditions held at $1,038 \sim 1,121^{\circ} \mathrm{C}$ for 0.5 to 1.0 hours per $2.54 \mathrm{~cm}$ of material thickness were verified to be sufficiently contributing to the prevention of intergranular corrosion of the material sensitized at $675^{\circ} \mathrm{C}$ for 1 hour per $2.54 \mathrm{~cm}$ of material thickness, and the detailed results are as follows.

1) $2.54 \mathrm{~cm}$ thick coupons subjected to sensitization heat treatment at $675^{\circ} \mathrm{C}$ for 1 hour were rejected in ASTM A262 test due to a large amount of chromium carbide precipitated in the form of grains 50 to $300 \mathrm{~nm}$ in diameter at the grain boundary and showed DOS of about $10.8 \%$ in the DL-EPR test. However, as a result of solution heat treatment of the sensitized specimen at $1,038^{\circ} \mathrm{C}$ and $1,121^{\circ} \mathrm{C}$ for 1 minute, chromium carbide was completely dissolved into the grains, passed the ASTM A262 test, and showed a DOS of $0.01 \%$ or less in the DL-EPR test.

2) As a result of performing solution heat treatment at $675^{\circ} \mathrm{C}$ for 5 hours at $1,038^{\circ} \mathrm{C}$ of $25.4 \mathrm{~cm}$ thick coupon subjected to sensitization heat treatment for 10 hours, the specimens passed the ASTM A262 test and the DL-EPR test regardless of its location per material thickness. On the surface, a step structure with no precipitation of chromium carbide at all and DOS of $0.01 \%$ or less were observed. As moving toward the center, some dual structures were observed due to longer exposure than in the surface to the sensitization temperature range of $427 \sim 816^{\circ} \mathrm{C}$ in the cooling process, and DOS of about $0.6 \%$ was obtained. Nevertheless, considering that the area directly affected by intergranular corrosion is the surface part rather than the center part, it is thought that the nuclear facility components will not be affected in the operation environment.

3) Considering the holding time of 1 minute during which the chromium carbide precipitated at the grain boundary at $1,038^{\circ} \mathrm{C}$ is completely dissolved into the grains, as well as the analysis result in which the center reached $1,038^{\circ} \mathrm{C}$, the solution heat treatment temperature, later than the surface by 18.3 minutes at the thickness of $25.4 \mathrm{~cm}$, the maximum thickness used in the nuclear power industry, the holding time for complete solution heat treatment to the center of the material is determined to be 2 minutes at maximum per $2.54 \mathrm{~cm}$ of the material thickness.

ORCID: Eun-Jong Oh: https://orcid.org/0000-0002-4907-7936 ORCID: Dong-Hwa Lee: https://orcid.org/0000-0001-9082-1934 ORCID: Sung-Woo Cho: https://orcid.org/0000-0002-1393-9880 ORCID: Yun-Il Choi: https://orcid.org/0000-0003-2929-0550 ORCID: Ki-Woo Nam: http://orcid.org/0000-0001-7019-358X

\section{References}

1. Sehwa editorial department, Stainless Steel Handbook, Sehwa, Seoul, Korea (1992) 60-69, 685-686.

2. Setion II Part A \& D of ASME Boiler and Pressure Vessel Code, The American Society of Mechanical 
Engineers (ASME) (2019).

3. B. H. Jung, M. G. Kim, Effect of Thermal Cycle and Stress on the Intergranular Corrosion in 316 Stainless Steel, J. Korean Soc. Marine Eng. 30(6) (2006) 709-715.

4. ASTM A262, Standard Practices for Detecting Susceptibility to Intergranular Attack in Austenitic Stainless Steels, American Society for testing and materials (ASTM) (2014).

5. ASTM G108, Standard Test Method for Electrochemical Reactivation (EPR) for Detecting Sensitization of AISI Type 304 and 304L Stainless Steels, American Society for testing and materials (ASTM) (1994).

6. ISO-12732, Corrosion of metals and alloys-Electro chemical potentiokinetic reactivation measurement using the double loop method (based on Čihal's method), International Organization For Standardization (ISO) (2006).

7. S. Kolli, T. Ohligschlager, D. Porter, Quantitative Prediction of Sensitization in Austenitic Stainless Steel Accounting for Multicomponent Thermodynamic and Mass Balance Effects, ISIJ International, 59(7) (2019) 1330-1336. https://doi.org/10.2355/isijinternational.ISIJINT-2018-715
8. H. C. Choe, K. T. Moon, K. H. Kim, Effects of Heat Treatment on Intergranular Corrosion of AISI 304 Stainless Steel, J. Corros. Sci. Soc. Korea. 21(4) (1992) 239-248.

9. H. P. Kim, S. S. Hwang, C. K. Rhee, K. M. Kim, J. S. Kim, A Review of Sensitization of Stainless Steel, Corros. Sci. Technol. 27(1) (1998) 52-64.

10. Korean Welding and Joining Society, Welding and Joining Handbook, I: Steel and Non-ferrous Materials, Korean Welding and Joining Society, Daejeon, Korea (2008) 153-165.

11. R. V. Taiwade, A. P. Patil, S. J. Patre, R. K. Dayal, A Comparative Study of Intergranular Corrosion of AISI 304 Stainless Steel and Chrome-Manganese Austenitic Stainless Steel, ISIJ International, 52(10) (2012) 18791887.

https://doi.org/10.2355/isijinternational.52.1879

12. E. J. Oh, J. H. Lee, S. W. Cho, W. G. Yi, K. W. Nam, Effect of Carbon Content on Intergranular Corrosion of Welding Heat Affected Zone in 304 Stainless Steel, J. Weld. Join. 37(4) (2019) 322-332.

https://doi.org/10.5781/JWJ.2019.37.4.6 